Marquette University

e-Publications@Marquette

College of Nursing Faculty Research and

Publications

Nursing, College of

$11-1-2012$

\title{
Methodological Triangulation: An Approach to Understanding Data
}

Abir K. Bekhet

Marquette University, abir.bekhet@marquette.edu

Jaclene A. Zauszniewski

Case Western Reserve University

Accepted version. Nurse Researcher, Vol. 20, No. 2 (November 2012): 40-43. DOI. (C) 2012 RCN

Publishing Company. Used with permission. 


\title{
Methodological Triangulation: An Approach to Understanding Data
}

\author{
Abir K. Bekhet \\ College of Nursing, Marquette University \\ Milwaukee, WI \\ Jaclene A. Zauszniewski \\ Community Health Nursing, Case Western Reserve University, \\ Cleveland, $\mathrm{OH}$
}

\begin{abstract}
Aim: To (describe the use of methodological triangulation in a study of how people who had moved to retirement communities were adjusting.

Background: Methodological triangulation involves using more than one kind of method to study a phenomenon. It has been found to be beneficial in providing confirmation of findings, more comprehensive data, increased validity and enhanced understanding of studied phenomena. While many researchers have used this well-established technique, there are few published examples of its use.

Data sources: The authors used methodological triangulation in their study of people who had moved to retirement communities in Ohio, US.

Review methods A blended qualitative and quantitative approach was used. Discussion The collected qualitative data, complemented and clarified the quantitative findings, by helping to Identify common themes. Qualitative data also helped in understanding interventions for promoting 'pulling' factors and for overcoming 'pushing' factors of participants. The authors used focused research questions to reflect the research's purpose and four evaluative criteria - 'truth value', 'applicability', 'consistency' and 'neutrality' - to ensure rigour.
\end{abstract}


Conclusion: This paper provides an example of how methodological triangulation can be used in nursing research. It identifies challenges associated with methodological triangulation, recommends strategies for overcoming them, provides a rationale for using triangulation and explains how to maintain rigour.

Implications for research/practice: Methodological triangulation can be used to enhance the analysis and the interpretation of findings. As data are drawn from multiple sources, it broadens the researcher's insight into the different issues underlying the phenomena being studied.

Keywords: Methodological triangulation

\section{Introduction}

'METHODOLOGICAL TRIANGULATION' or mixed-methods research uses more than one kind of method to study a phenomenon (Risjord et al 2001, Casey and Murphy 2009). There are two types of methodological triangulation: 'across method' and 'within method'. Across-method studies combine quantitative and qualitative datacollection techniques (Boyd 2001, Casey and Murphy 2009). Qualitative methods are explanatory and textual, and include passive observation, participant observation and open-ended interviews or analysis of patient diaries (Risjord et al 2001). Quantitative methods include statistical analysis of outcomes or questionnaires, collected by standardized scales or measures and expressed numerically (Risjord et al 2001).

Within-method studies use two or more data-collection procedures, quantitative or qualitative, but not both. For example, quantitative data may be collected using two procedures - such as survey questionnaires and a pre-existing database - while qualitative data may be collected by using participant observation and interviews (Denzin 1989, Kimchi et al 1991, Thurmond 2001, Casey and Murphy 2009).

Methodological triangulation has been found to be beneficial in providing confirmation of findings, more comprehensive data, increased validity and enhanced understanding of the studied phenomenon (Redfern and Norman 1994, Risjord et al 2001, Foss and Ellefsen 2002, Halcomb and Andrews 2005, Casey and Murphy 2009).

Nurse Researcher, Vol. 20, No. 2 (November 2012): pg. 40-43. DOI. This article is (C) RCN Publishing Company and permission has been granted for this version to appear in e-Publications@Marquette. RCN Publishing Company does not grant permission for this article to be further copied/distributed or hosted elsewhere without the express permission from RCN Publishing Company. 
With triangulation, researchers can use two research methods to decrease the weaknesses of an individual method and strengthen the outcome of the study (Denzin 1978, Sharif and Armitage 2004).

While many researchers have used well-established methodological triangulation, there are few published examples of its use to enhance studies. This paper describes how we used methodological triangulation in a study to find out how older people who had moved to retirement communities were adjusting. We will identify challenges in using methodological triangulation and strategies to overcome these challenges. We will also highlight some strengths and weaknesses of methodological triangulation.

\section{Effects of moving to a new home}

Older people are a growing segment of the US population and their numbers are expected to grow to 71 million by the year 2030 (Centers for Disease Control and Prevention 2003, Bekhet et al 2008, 2009). The different types of life events that older people face in the US have become major areas of interest for social scientists and policymakers (Ferraro 1983, Naylor et al 2012). One of those events is moving home, which has potentially harmful effects on the wellbeing of older people (Ferraro 1983). Previous studies were inconclusive in determining the effects of moving home on the wellbeing of older people. Some studies reported negative consequences, such as depression and mortality (Capezuti et al 2006, Walker et al 2007, Bekhet et al 2008) while others reported positive consequences, such as emotional security and a sense of wellbeing (Reed and Payton 1996).

Determinations of factors and individual characteristics that contribute positively or negatively to moving home were also inconclusive: for example, while Haddad (1981) found that more men than women died after moving home, Bourestom and Pastalan (1981) showed the opposite to be true - more women died on moving home than men. But, Lazarus (1993) pointed out that other variables interact with gender and contribute to adaptation.

Nurse Researcher, Vol. 20, No. 2 (November 2012): pg. 40-43. DOI. This article is (C) RCN Publishing Company and permission has been granted for this version to appear in e-Publications@Marquette. RCN Publishing Company does not grant permission for this article to be further copied/distributed or hosted elsewhere without the express permission from RCN Publishing Company. 
Given the lack of conclusive evidence in the available literature, we identified a need to understand how older people adjusted to moving home, the potential moderating function of an individual's resourcefulness and the role played by relocation factors and the characteristics in affecting the relationship between moving home and adjustment to that new home. We thought that the complexity of the process meant methodological triangulation would strengthen our results. We therefore used quantitative and qualitative approaches in our study of 104 older people who had relocated to six retirement communities in Ohio (Bekhet et al 2008, 2009).

Studies have found that moving home has physical and emotional consequences that depend on older people's circumstances, their physical and mental health during the move, and their preparation for and perceived control over the move (Mikhail 1992, Bekhet et al 2008). However, no previous research had investigated whether or not individuals' resourcefulness mediated or moderated adjustment to a new home (Bekhet et al 2008). Furthermore, no studies have used standardized measures to look at the effects on adjustment of the ability to make decisions regarding the move.

We used a quantitative approach with a questionnaire, the 'Index of Relocation Adjustment' (IRA), that elicits responses using standardized numeric scales (Bekhet et al 2008) A four-point Likert scale was used with item responses ranging from completely agree to completely disagree.

We also used qualitative interviews with open-ended questions to ask people about their reasons for moving (Bekhet et al 2009) to collect qualitative data (field notes) during the interviews and to observe the environmental characteristics of the sites. The study has been reported elsewhere (Bekhet et al 2009).

We used the standardized IRA to measure two related dimensions of adjustment: 'congruence' and 'continuity'. 'Congruence' established the degree participants felt they belonged and their control and independence had continued as before; 'continuity' established the 
connection between participants' past and current living situations (Prager 1986, Bekhet et al 2008).

Themes from the qualitative interviews clarified this finding, reflecting 'pushing' factors, 'pulling' factors and 'overlapping' factors that affected participants' adjustment (Bekhet et al 2009). Some 'pulling' factors involved participants' having moved voluntarily or having control over their moves, which in turn contributed to their adjustment (Bekhet et al 2009); related themes included the location, familiarity and reputation of the community's emotional security and joining friends (Bekhet et al 2009). For example, an 88-yearold participant said that having friends in the retirement community was a reason for his move and a main factor in his adjustment. He expressed the 'continuity' part of adjustment clearly: 'I have friends here... We aU went to school together... graduated at the same time... and shared every single moment together... It was nice and fun joining them here... I mean, you feel that they are part of your past and...your future as well' (Bekhet et al 2009).

'Pushing' or coercing factors obtained from the qualitative data indicated a degree of involuntary relocation or not having control over the move, which in turn hindered participants' adjustment (Bekhet et al 2009). Factors included participants' or spouses' failing health, relinquishing responsibilities, a need to rely on family members for help with daily living rather than receiving professional assistance, previous communities being dosed and loneliness (Bekhet et al 2009). These data complemented and clarified the quantitative data, showing that the less control participants had over their moves, the less they adjusted to the moves.

The quantitative data indicated that the type of retirement communities (assisted or independent living) correlated with adjustment. However, because there were unequal numbers of people in the two categories, we could not compare those in assisted living and those in independent-living communities. The qualitative data collected complemented and clarified the quantitative findings through the common themes formed, such as the pushing factors of moves to assisted-living communities compared with the pulling factors for moves to independent-living communities (Bekhet et al 2009). 
The pushing factors in the assisted-living group included declining health, not having access to professional help to carry out everyday activities, whereas the pulling factors of the participants in independent-living communities focused on the familiarity of the community, joining friends who have already moved to the retirement communities, and the location (Bekhet et al 2009). The assisted-living residents were pushed into their communities and adjusted poorly compared with the independent-living residents, who felt pulled toward their new homes and adjusted better (Bekhet et al 2009). Thus, the qualitative data provided a richer understanding of the quantitative data by clarifying the correlation between the type of community (assisted or independent living) and adjustment.

Qualitative data also helped us to understand the interventions that promoted pulling factors and overcame pushing factors. For example, familiarization of participants with their new homes through orientation sessions or evaluations of the care provided were seen as positive pulling factors. To enhance their sense of security, residents could be encouraged to express their feelings about their moves (Coughlan and Ward 2007, Bekhet et al 2008, 2009) and to participate in social activities (Oldman and Quilgars 1999, Reed et al 1999, 2003, Bekhet et al 2009). One of the pulling themes was 'joining friends', which demonstrated the importance of creating relationships among staff and other residents (Capezuti et al 2006, Bekhet et al 2009).

\section{Discussion}

The authors used qualitative and quantitative methods simultaneously and the findings from the two methods were complementary. This is referred to as 'simultaneous' (Casey and Murphy 2009) or 'across method' triangulation (Boyd 2001). In keeping with a qualitative perspective, the primary aim of the triangulation was to ensure completeness of data, using quantitative and qualitative approaches to identify any similarities and differences.

Limitations of triangulation in the literature include using incorrect methods and the inability to articulate its use dearly (Oberst 1993). But, there are multiple strategies for overcoming these

Nurse Researcher, Vol. 20, No. 2 (November 2012): pg. 40-43. DOI. This article is (C) RCN Publishing Company and permission has been granted for this version to appear in e-Publications@Marquette. RCN Publishing Company does not grant permission for this article to be further copied/distributed or hosted elsewhere without the express permission from RCN Publishing Company. 
limitations. It is important to have a research question that is focused, concise and relevant (MitcheU 1986, Dootson 1995, Begley 1996, Casey and Murphy 2009).

In our study, we used focused questions that reflected the purpose of our research in an attempt to overcome triangulation challenges. Our quantitative study question addressed the effects of control and resourcefulness on adjustment to the move. This was appropriate for our mixed methods of data collection because it complemented the qualitative data by asking the participants two open-ended questions: 'What led you to come here?' and 'What was it like to come to live here?' (Bekhet et al 2009).

We collected quantitative data to identify the relationships among the factors involved in moving home. These factors were: type of assisted-living community, place from which the participant was transferred, perceived social support from family and friends, daily activities, preparation for the move, change in environment, time since the move, resourcefulness and adjustment to the move, and to examine the effects of control and resourcefulness on adjustment (Bekhet et al 2008). Creating an understanding of the use of triangulation is a strategy for overcoming challenges (Miles and Huberman 1994, Shih 1998, Casey and Murphy 2009) and we used triangulation to create a better understanding of the data and to ensure their completeness.

In addition, the literature suggests that each method of data collection should be independently complete (Denzin 1978, Morse 1991, Johnson et al 2001, Casey and Murphy 2009). We ensured that each method was rigorous and complete We used the four evaluative criteria suggested by Casey and Murphy (2009) - 'truth value', 'applicability', 'consistency' and 'neutrality' - to ensure rigour.

We first made sure that the qualitative data were credible by having two experienced nurse researchers independently code the data. We then compared the coding schemes and found agreement between them was greater than 95 per cent. We ensured the data were rigorous by having the two nurse researchers independently 
specify the conceptual dimensions, the data and the categorization (Bekhet et al 2009), and by conducting interviews separately if couples moved together, which was the case for three couples (Bekhet et al 2009).

In our qualitative study, we achieved credibility and truth value ('internal validity' in quantitative research) by using quotations that objectively captured individuals' experiences (Guba and Lincoln 1989), indicating 'neutrality' ('confirmability' in qualitative research; objectivity in quantitative research. We achieved 'applicability' ('transferability' in qualitative research and 'external validity' in quantitative research) by reaching saturation (Casey and Murphy 2009), with new data continuing to be collected without additional themes arising (Guba and Lincoln 1989). We achieved 'consistency' ('auditability' or 'dependability' in qualitative research, similar to 'reliability' in quantitative research) because our ideas were conveyed to the reader (Bekhet et al 2009).

Rigour was assured in the quantitative data collection because reliability of all measures exceeded the minimum criterion of acceptable internal consistency (.70 Cronbach's a). We demonstrated construct validity for the adjustment measure by using the Pearson correlation coefficient which gave significant correlations in the expected directions $(P<.001)$ with measures of positive thoughts and control ( $r=.36$ and -.44 respectively). We evaluated the assumptions for multiple regression to ensure that there were no violations and used a correlation matrix to examine relationships among the major study variables and factors involved in moving.

\section{Conclusion}

This paper provides an example of how methodological triangulation can be used effectively in nursing research. It identified challenges associated with methodological triangulation, and recommended strategies for overcoming them by providing a rationale for using triangulation and explaining how to maintain rigour in research. 
NOT THE PUBLISHED VERSION; this is the author's final, peer-reviewed manuscript. The published version may be accessed by following the link in the citation at the bottom of the page.

\section{References}

Begley CM (1996) Using triangulation in nursing research. Journal of Advanced Nursing. 24, 1, 122-128.

Bekhet AK, ZauszniewsM JA, Wykle ML (2008) Milieu change and relocation adjustment in elders. Western Journal of Nursing Research. 30, 1, 113-129

Bekhet AK, ZauszniewsW JA, Nakhla WE (2009) Reasons for relocation to retirement communities: a qualitative approach. Western Journal of Nursing Research. 31, 4, 462-479.

Bourestom N, Pastalan L (1981) The effects of relocation on the elderly. The Gerontologist. 21, 1, 4-7.

Boyd CO (2001) Combining qualitative and quantitative approaches. In Munhall PL (Ed) Nursing Research: A Qualitative Perspective. Third edition. Jones and Bartlett, Sudbury MA.

Capezuti E, Boltz M, Renz S et al (2006) Nursing home involuntary' relocation: clinical outcomes and perceptions or residents and families. Journal of the American Medical Directors Association. 7, 8, 486-492.

Casey D, Murphy K (2009) Issues in using methodological triangulation in research. Nurse Researcher. 16, 4, 40-55.

Centers for Disease Control and Prevention (2003) Public health and aging: trends in aging - United States and worldwide. Morbidity and Mortality Weekly Report. 52, 6, 101-106.

Coughlan R, Ward L (2007) Experiences of recently relocated residents of a long-term care facility' in Ontario: assessing quality qualitatively. International Journal of Nursing Studies. 44, 1, 47-57.

Denzin NK (1978) The Research Act: A Theoretical Introduction to Sociological Methods Second edition. McGraw-Hill, New York NY.

Denzin NK (1989) The Research Act: A Theoretical Introduction To Sociological Methods. Third edition. Prentice Hall. New York NY.

Dootson S (1995) An in-depth study of triangulation. Journal of Advanced Nursing. 22, 1, 183-187.

Ferraro KF (1983) The health consequences of relocation among the aged in the community. Journal of Gerontology. 38, 1, 90-96.

Foss C, Ellefsen B (2002) The value of combining qualitative and quantitative approaches in nursing research by means of method triangulation. Journal of Advanced Nursing. 40, 2, 242-248.

Guba EG, Lincoln YS (1989) Fourth Generation Evaluation. Sage Publications, Newbury Park, CA.

Haddad LB (1981) Intra-institutional relocation: measured impact upon geriatric patients. Journal of the American Geriatrics Society. 29, 2, 86-88.

Halcomb E, Andrew S (2005) Triangulation as a method for contemporary nursing research. Nurse Researcher. 13, 2, 71-82.

Nurse Researcher, Vol. 20, No. 2 (November 2012): pg. 40-43. DOI. This article is (C) RCN Publishing Company and permission has been granted for this version to appear in e-Publications@Marquette. RCN Publishing Company does not grant permission for this article to be further copied/distributed or hosted elsewhere without the express permission from RCN Publishing Company. 
NOT THE PUBLISHED VERSION; this is the author's final, peer-reviewed manuscript. The published version may be accessed by following the link in the citation at the bottom of the page.

Johnson M, Long T, White A (2001) Arguments for 'British pluralism' in qualitative health research. Journal of Advanced Nursing. 33, 2, 243249.

Kimchi J, Polivka B, Stevenson JS (1991) Triangulation: operational definitions. Nursing Research. 40, 6, 364-366.

Lazarus RS (1993) From psychological stress to the emotions: a history' of changing outlooks. Annual Review of Psychology. 44, 1-21.

Mikhail ML (1992) Psychological responses to relocation to a nursing home. Journal of Gerontological Nursing. 18, 3, 35-39.

Miles MB, Huberman AM (1994) Qualitative Data Analysis: An Expanded Sourcebook. Second edition. Sage Publications. London.

Mitchell ES (1986) Multiple triangulation: a methodology' for nursing science. Advances in Nursing Science. 8, 3, 18-26.

Morse JM (Ed) (1991) Qualitative Nursing Research: A Contemporary Dialogue. Revised edition. Sage Publications, Newbury Park CA.

Naylor MD, Kurtzman ET, Grabowski DC et al (2G12) Unintended consequences of steps to cut readmissions and reform payment may threaten care of vulnerable older adults. Health Affairs. 31, 7, 16231632.

Oberst MT (1993) Possibilities and pitfalls in triangulation. Research in Nursing and Health. 16, 6, 393-394.

Oldman C, Quilgars D (1999) The last resort? Revisiting ideas about older people's living arrangements. Ageing and Society. 19, 3, 363-384.

Prager E (1986) Components of personal adjustment of long distance elderly movers. The Gerontologist. 26, 6, 676-680.

Redfern SJ, Norman IJ (1994) Validity through triangulation. Nurse Researcher. 2, 2, 41-56.

Reed J, Cook G, Stanley D (1999) Promoting partnership with older people through quality' assurance systems: issues arising in care homes. Nursing Times Research. 4, 5, 353-363.

Reed J. Cook G, Sullivan A et al (2003) Making a move: care-home residents' experiences of relocation. Ageing \& Society. 23, 2, 225-241.

Reed J, Payton VR (1996) Challenging the institution. Journal of Psychiatric and Mental Health Nursing. 3, 4, 274-277.

Risjord M, Moloney M, Dunbar S (2001) Methodological triangulation in nursing research. Philosophy of the Social Sciences. 31, 1, 40-59.

Sharif F, Armitage P (2004) The effect of psychological and educational counselling in reducing anxiety' in nursing students. Journal of Psychiatric and Mental Health Nursing. 11, 4, 386-392.

Shih FJ (1998) Triangulation in nursing research: issues of conceptual clarity and purpose. Journal of Advanced Nursing. 28, 3, 631-641.

Thurmond VA (2001) The point of triangulation. Journal of Nursing Scholarship. 33, 3, 253-258.

Nurse Researcher, Vol. 20, No. 2 (November 2012): pg. 40-43. DOI. This article is (C) RCN Publishing Company and permission has been granted for this version to appear in e-Publications@ Marquette. RCN Publishing Company does not grant permission for this article to be further copied/distributed or hosted elsewhere without the express permission from RCN Publishing Company. 
NOT THE PUBLISHED VERSION; this is the author's final, peer-reviewed manuscript. The published version may be accessed by following the link in the citation at the bottom of the page.

Walker CA, Curry LC, Hogstel MO (2007) Relocation stress syndrome in older adults transitioning from home to a long-term care facility: myth or reality? Journal of Psychosocial Nursing and Mental Health Services. $45,1,38-45$.

Nurse Researcher, Vol. 20, No. 2 (November 2012): pg. 40-43. DOI. This article is (C) RCN Publishing Company and permission has been granted for this version to appear in e-Publications@Marquette. RCN Publishing Company does not grant permission for this article to be further copied/distributed or hosted elsewhere without the express permission from RCN Publishing Company. 